\title{
Topography of the Internal Organs of the Brown Bullhead (Ameiurus nebulosus) Lesueur, 1819 (Actinopterygii: Ictaluridae)
}

\author{
Florentina POPESCU ${ }^{11}$, Călin LAȚIU ${ }^{11}$, Daniel $\operatorname{COCAN}^{11}$, Vioara MIREŞAN ${ }^{1) *}$ \\ 1) Faculty of Animal Sciences and Biotechnologies, University of Agricultural Sciences and Veterinary \\ Medicine of Cluj-Napoca, 3-5 Manastur Street, Cluj-Napoca, Romania \\ *Corresponding author, e-mail: vmiresan@yahoo.com
}

Bulletin UASVM Animal Science and Biotechnologies 72(2) / 2015

Print ISSN 1843-5262; Electronic ISSN 1843-536X

DOI:10.15835/buasvmcn-asb:11422

\begin{abstract}
The problem of invasive species of fish is a major issue, both internationally and nationally. The presence of invasive species is often associated with acclimatization of new species of fish, activities correlated with the absence of effective control and quarantine programs. In other words, when new desired species are imported, other accompanying species are also brought in often in the form of embryonated eggs or juveniles. The brown bullhead, which we have studied, is also an invasive species of fish in Stejeris Lake, Cluj County. This species is of interest, both scientifically and economically. From the scientific point of view, brown bullhead has a high capacity of resistance to environmental changes, unfavourably conditions, which ensures a perpetuation of the species in almost every aquatic environment. Even though it is recognized that the economic impact of this invasive species is significant, not much information is available at present, and neither is there much data about the topography of its internal organs, which is being studied in this paper.
\end{abstract}

Keywords: brown bullhead, internal topography, dissection, organs

\section{INTRODUCTION}

Brown bullhead, which is considered an invasive species, has been studied from the standpoint of behaviour and spread, and due to its resistance to various sources of pollution, in laboratory studies as well. The literature is still poor in terms of anatomical descriptions of both external conformation, anatomy and internal topography of the organs (Scott and Crossman, 1973; Mandrak, 2009). For studying the internal structure of the brown bullhead, we used the protocols described by Șanta et al. (1962).

\section{AIMS AND OBJECTIVES}

By studying some morphological aspects and the topography of the brown bullhead's internal organs, we aimed to contribute to the improvement of specialist literature.

\section{MATERIALS AND METHODS}

We collected five specimens of brown bullhead from Stejeriş Lake (Cluj country) and prepared them for dissection by initially anesthetising them with Eugenol. They were fixed in dorsal decubitus, and a transversal incision was performed. From the middle of this incision, on the medial-ventral line, a longitudinal section of the abdominal wall was performed, to the right of the pectoral fins, revealing the internal organs and the viscera (Fig.1). Based on macroscopic observations, we performed an anatomical description of the internal organs and viscera. The anatomical parts were photographed, analysed and described in detail.

\section{RESULTS AND DISCUSSION}

As mentioned above, the specialty literature is poor as concerns this species, which is why the 


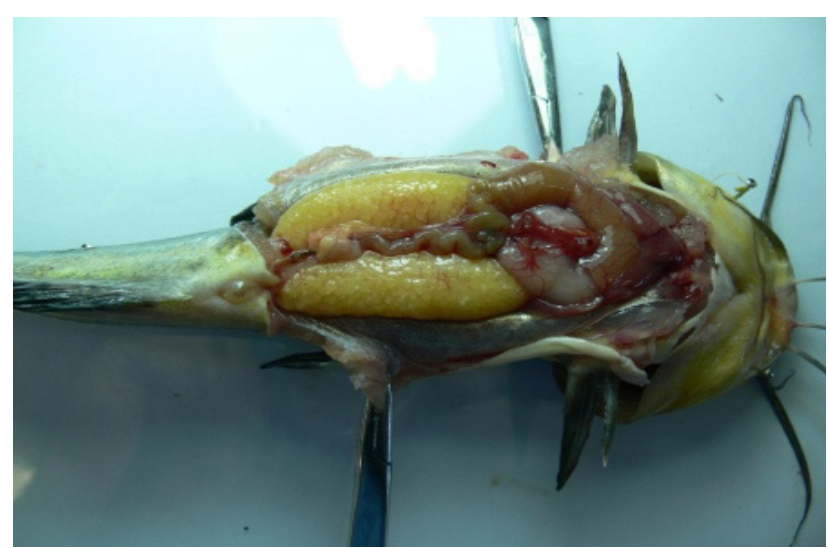

Fig. 1 The internal organization of brown bullhead (Ameiurus nebulosus)

obtained data could not be compared to existing data. The study provides new details about the anatomy of the species.

The largest part of the general cavity was observed to be occupied by highly developed ovaries (stage IV), as all the specimens were female collected in the breeding period (Fig.1 and Fig. 2-c). In the lower caudal part, the first segment of the medium intestine is revealed through an opening sphincter corresponding to the pyloric sphincter. The stomach is L-shaped, well developed, with an evident muscular wall and a vascularized external serous. Noteworthy is the absence of pyloric caeca. In the general cavity, a bilobated liver is highlighted (Fig. 2-a) accompanied by a highly developed gallbladder (Fig. 2-b). Both the stomach and the first segment of the midgut are highly vascularised, both showing a transparent serous on the external surface. The first segment of the midgut (duodenum) continues with the hind gut, which appears slightly corrugated, its loops project on medial-ventral line of the general cavity between the two lobes of the ovaries. The gas bladder is very well developed, bilobate heart shaped, with walls that are more developed compared to other species of fish (Fig.2-d). The kidneys are triangular in shape and are supported by a peritoneum by the dorsal wall in the general cavity (Fig. 2-e). We noticed two orifices, caudally positioned from the anal fin, a common orifice (cloaca) for digestive and excretory purposes, and a genital orifice.

The highly developed gall bladder points at the nutritional spectrum of this species. Nutrition consists of numerous lipids along with other constituents. The colour of the liver is pale pink
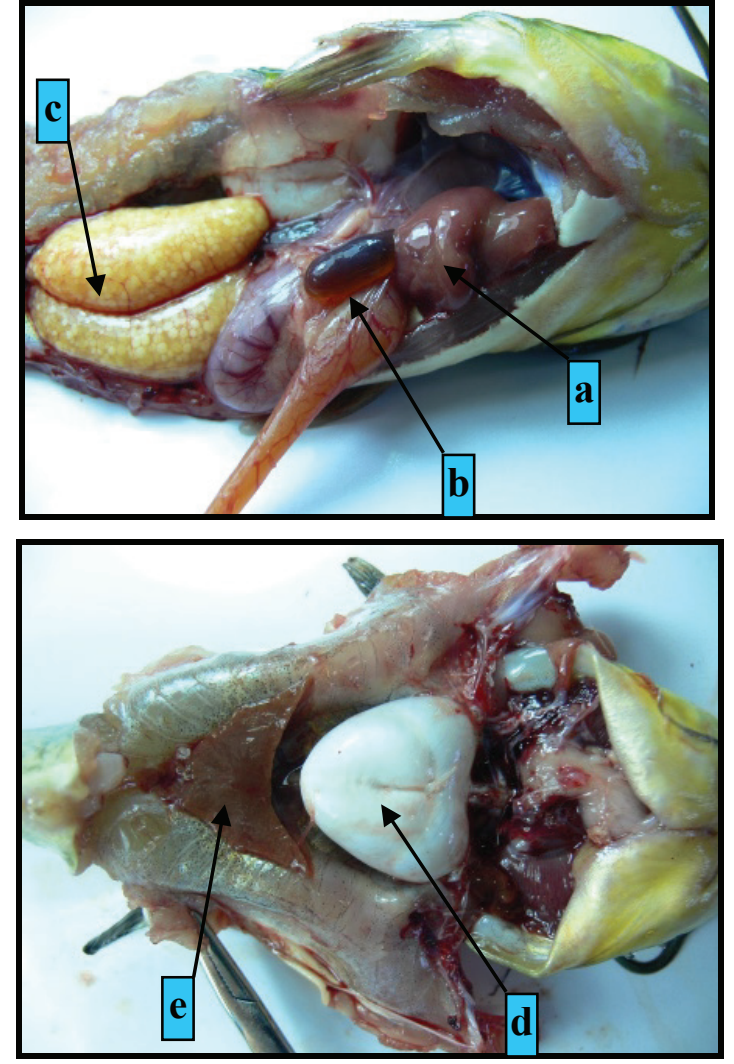

Fig. 2 Macroscopic aspects of internal organs: Liver (a); Gallbladder (b); Ovaries (c); Air bladder (d), Kidneys (e).

due the reproductive period, when the species feeds less intensively. The colour of the bile is yellowish brown, and the gall bladder membrane is almost transparent. Air bladder volume is closely correlated with the ability of the species to adapt to unsuitable environmental conditions, high temperatures and a lower level of dissolved oxygen.

\section{CONCLUSION}

Our study has contributed to enhancing knowledge about this species of invasive fish.

\section{REFERENCES}

1. Șanta N, Bogoescu C, Stoica M, Boldor Ș, Andreescu B, Popovici LA. (1962) Demonstrații şi lucrări practice de zoologie, anatomie şi fiziologie. Ed. de Stat Didactică şi Pedagogică, București.

2. Scott WB, Crossman EJ. (1973). Freshwater Fishes of Canada. Bulletin 184, Fisheries Research Board of Canada, p.966.

3. Litvak MK, Mandrak NE, (1993). Ecology of freshwaterbaitfishuse in Canada and the United States. Fisheries, 18(12): 6-13. 